\title{
Friending with a teacher as a way of forming meaningful life strategies of a future educator
}

\author{
E.I. Koykova ${ }^{1 *}$, V.A. Buzni' $^{2}$, and N.A. Lobachova ${ }^{3}$ \\ ${ }^{1}$ V.I. Vernadsky Crimean Federal University, Simferopol, Russia \\ ${ }^{2}$ V.I. Vernadsky Crimean Federal University, Simferopol, Russia \\ ${ }^{3}$ V.I. Vernadsky Crimean Federal University, Simferopol, Russia
}

\begin{abstract}
The article contains an analysis of the concept of a semantic sphere as a structure-forming component of a person's meaningful life strategies. The necessity of using friending as a way to form life-sense orientations of a future teacher, as well as the importance of selfactualization and self-development for successful professional activity are substantiated. The article analyzes structural components of the meaningful concept of the personality of a future teacher. The study presents diagnostic tools, the results of the experiment, as well as a program for the formation of meaningful life strategies for a future teacher.
\end{abstract}

\section{A problem statement}

In the process of socialization of a person, one of the stages of personal development is the development of a particular profession. An important role in this is played by the quality of education, which contributes to the formation of the semantic sphere of a future specialist both in general and in the mainstream of a chosen direction. The problem of choosing a semantic strategy for students in comprehending new knowledge, with the help of what tactics he implements it, remains relevant.

In addition, a teacher is also acutely faced with the issue of choosing tactics for effective interaction with students in order to form their life guidelines, which contribute to both personal development of students in general and formation of a future specialist in particular.

One of the effective tactics aimed at the formation of life-meaningful strategies of students is acquiring friendship with a teacher, which allows one to successfully build a trajectory for mastering educational content, contributes to the development of personal qualities and the improvement of necessary competencies of students in the field of professional activity.

Considering the range of life-meaning strategies, it should be noted that the foundation of the search for ways of implementation is the semantic sphere. Facts of the dynamics of the formation of meaning and building a life path are meaning growth, ascent, enrichment. Turning to the origins of classical psychology, namely the "development zones" identified by L.S. Vygotsky, stages of entry into the development zones can be described as the

${ }^{*}$ Corresponding author: prof-ped.gpa@mail.ru 
following: it is during the professional formation that the "self-development zone" is decisive in the formation of meaning. The driving force of the sense-formation strategy is the "zone of proximal development of the semantic sphere of a personality" [1]. The life world of a teacher's personality, his relationship to it, whether it is a significant subjective experience, a less expressive attitude, or an experience having less vital significance, this is defined as life meanings (senses) of a personality. Meanings of life go through the processes of formation, development and depend on the needs of each subject.

The particular relevance of this work lies in the fact that our study not only established the presence of a hierarchy of semantic orientations of future teachers, but also carried out a deeper study of the problem, taking into account the semantic context, with the characteristics of the time perspective possessed by student youth.

In the field of semantic pedagogy, research by A.G. Asmolov, who claims that "these are semantic attitudes that ultimately determine the stability and direction of the behavior of an individual, his actions and deeds" [2], is of topical interest. The author reveals specifics of the manifestation of individuality in situations of personal choice based on following social stereotypes for mastering one's own behavior. Considering that education, as a form of social practice, covers all spheres of human life, a teacher can significantly influence the life-meaning strategies of students.

The problem of meaning formation is widely presented in the scientific works of A.G. Asmolov "Semantic Pedagogy", I.A. Vasilyeva "Semantic regulation of mental activity", I.V. Abakumova, P.N. Ermakova, V.T. Fomenko "Semantic didactics". So, A.G. Asmolov introduces the concept of a semantic attitude as a form of expression of personal meaning in the form of readiness to perform a certain way of directed activity. "Personal meaning is the content of an attitude" [2]. The very same personal meaning is understood as the result of interiorization and embodiment in the consciousness of the objective relations of an individual in the outer world. Personal meaning of something is a reflection of the content of a personality's relationship to reality. In addition, it reflects the unity of affective and intellectual processes [2]. Thus, personal meaning is the upper stage in the attitudinal regulation of activity. Semantic attitudes, being relevant motives of activity, along with target and operational attitudes, constitute the hierarchy of attitudinal regulation of activity. They perform the function of stabilizing activity as a whole: "These are the semantic attitudes that ultimately determine the stability and direction of the behavior of an individual, his actions and deeds".

In the studies of I.V. Abakumova, A.G. Asmolova, V.P. Zinchenko, V.V. Znakova, E.V. Klochko etc. it is convincingly proved that all life manifestations are subordinated to the semantic sphere of a personality, which determines the direction of human cognition [1, 3].

In the mainstream of semantic didactics, in our opinion, the developments of I.V. Abakumova, I.A. Rudakova, P.N. Ermakova, V.T. Fomenko and others, who offer a teacher pedagogical tools to stimulate students to meaningful activity $[1,3]$, are relevant.

Within the framework of our topic, we will consider one of the ways of forming meaningful life strategies of future teachers by using the method of friending with a teacher.

Speaking about experiencing friendship with an educator, we are talking not only about subject-subject interaction, partnerships, but about the uniqueness of friendliness, understanding and acceptance of a student as a part of himself, the symmetry of relations in which the student and the teacher are equal from the point of view of a psychological position. The need sphere, motivational, judgment and modes of action unite two subjects. It should be noted that subject-subject relations in the educational process affect not only cognition, but also self-development and professional development. Thus, taking into account the subjectivity, the uniqueness of each personality, a teacher finds himself in a 
field of uncertainty: the uncertainty of his motives, his own activities, thoughts, feelings. Such independence of the student, the ability to structure, plan his activity and be responsible for it - all this has undoubted advantages and a positive impact on life selfdetermination and the development of a life strategy.

Taking into account the meaning of friending as a way of forming meaningful life strategies of a future teacher, it is necessary to analyze the semantic meaning of an Englishlanguage word. So, the concept of friending, which appeared in the XXI century in the field of marketing, means interactive cooperation in a social network in order to establish friendly relations both for everyday virtual communication and for achieving commercial goals.

Friending is an activity based on friendliness, interactive cooperation, interpersonal communication, grounded on taking into account the needs of each of the communication participants.

The main condition for friending is the correlation of communication tools with voluntariness, cooperation, satisfaction and identification of the needs of those in contact. The task of friending is informing, providing support for professional development, personal growth at the request of a person. The process of obtaining information of diverse content is already considered not as an unanswered transmission, without waiting for the student's reaction, but as a hobby, at a time when the student, at the stage of cooperation with the friending information received from the teacher, will already give an answer and demonstrate his own ideological attitudes.

\subsection{The objective of the work}

The aim of writing the article is to substantiate the criteria and indicators for measuring the formation level of life-meaning strategies of a future teacher and to present the results of approbation of the program for the formation of life-meaning strategies of a future teacher in the process of friending. The presented diagnostic tools correspond to the selected indicators of the formation of the life-meaning strategies of future teachers.

\section{Results of the research}

The emergence, formation and development of personal meanings in the subjective world is associated with the life situation, needs, personality traits, motivations and vital necessities of a person. A phenomenon or object from the outside world that has fallen into a person's living space can contribute to the formation of personal meaning. So, it is voluntariness, the presence of feedback or the presence of two-way communication, the number of cooperation channels, clarification of the needs of communication participants, involvement in joint actions that will contribute to the formation of a meaningful strategy for future teachers.

In our study, we analyzed the scientific works of O.V. Telnova "Life-meaning strategies of gifted adolescents", A.A. Levshina "Life-meaning strategies of active social behavior of various groups of young people", I.V. Ulyanova "The educational system for the formation of life-meaning orientations in secondary school students", S.V. Shkileva "Life-meaning orientations as a factor of socio-psychological adaptation of students in the process of studying at a university" [4-7].

O.V. Telnikova notes that the world of human life presents a source of life-meaning formation strategy and defines life-meaning strategies as a system of personal meanings of an individual, which allows to optimize or minimize a subject's activity in relation to objective reality, as well as in relation to the goal, process, result of action as well as how life is manifested. The semantic orientation is formed on the basis of life experience, which 
is individual for everyone and includes both mental and practical actions experienced by a person, and personal meanings, attitudes, stereotypes. That is why friending can be considered as an individual and qualitatively influencing personality of the learner, which has an impact on the cognitive, creative and behavioral spheres [5].

Special attention of A.A. Levshin in the formation of meaningful life strategy assigns meaningful life concept of a personality. The main components of personal meaning of life concept that determine the readiness of a young person for professional activity are such characteristics as personal orientation, value sphere and motivation. Namely, a teacher is able, in the process of friendly interaction, to motivate for success and achievements, allowing them to realize their goals and desires in reality. The author identifies the value, semantic, motivational sphere of the orientation of a personality by structural components of the formation of life-meaning strategies [5].

The meaning of life is not only the future, not only the perspective, but also a measure of what a person has achieved, an assessment of what he has achieved on his own. This statement was put forward by S.V. Shkil in his scientific work, he noted that human life is motivated by a search for the meaning of its existence, a desire to realize this meaning on the basis of values. Life-meaning orientations as an expression of aspirations of a future teacher, his professional needs, as a confirmation of his real achievements, real ability to express himself in various forms of life. Analyzing the research of Sergei Vladimirovich, it should be noted that the interaction of "internal" and "external" contributes to balancing and counteracting the one-sided path of development, in this process a teacher, building the educational process and accompanying a future teacher, orients the person towards open mutual cooperation, through modern and popular means of communication [7].

I.V. Ulyanova, studying the phenomenon of "meaningful life orientations of students", came to the conclusion that an integral pedagogical process should have a basis that will include personality-developmental, regulatory-preventive, life-saving potential. In the structure of "life-meaning orientations" the researcher identifies: values, goals, activities and points out that the totality of spheres that cover both the external space and the internal environment of a person are of great importance for the formation of life-meaning orientations. Thus, the formation of life-meaning strategies is possible in the environment: subject-psychophysical, activity-creative, spiritual and moral. Diagnosing students, I.V. Ulyanova, identified social-pedagogical and pedagogical criteria [6].

Studying the components of life-meaning strategies, in order to determine the main criterion of formation, the following researches were analyzed: works of L.S. Vygotsky, who defined the dynamic semantic system as the equality of emotional and intellectual processes of consciousness; no less significant is the study by D.A. Leont'ev, he viewed the semantic system as a relatively stable and autonomous hierarchically organization, including a set of semantic structures functioning as a single whole [8]. From the point of view of V.E. Chudnovsky, "the meaning of life is not just some idea that is assimilated or developed by a person, but a special mental formation, which has its own specifics of origin, its stages of formation and, acquiring relative stability and liberation from the conditions that gave rise to it, can significantly affect a person's life, his fate" [9].

Each person is original and the personal-semantic sphere has its own development - this has the greatest influence on the cognitive orientation of an individual, which actually determines the development of life-semantic strategies in the cognitive process.

During the student period, the formation of the semantic sphere of a personality is relevant for the personality of a young person, at the same age a person gets the opportunity to act, to act independently, based on the given meanings of life. The following were identified as the main components for the formation of life guidelines in students: professional motivation, volitional attitudes, spiritual core, self-development, value 
orientations, the ability to reflect, the formation of their own image of the world, predictive abilities, professional self-determination.

Thus, in the process of the diagnostic cut, we were guided by the motivationalcognitive, axiological-social, personality-developmental criteria.

The motivational and cognitive criterion is characterized by a variety of interests, cognitive orientation and the desire of students for self-knowledge.

The axiological-social criterion presupposes a striving for the values of both personal life and professionally oriented, students are interested in the social significance of the results of their activities, social activity reflects the semantic sphere of the individual.

The personality development criterion covers the student's personal sphere, his ability for reflection, criticality, striving for self-actualization and self-determination. The formation of an active life position is also included.

When diagnosing the initial level of formation of the life-meaning strategies of future teachers, tasks were proposed in the form of tests. On the open learning platform Moodle, students had to complete test tasks by D.A. Leontyeva "Test of meaningful life orientations (method of LSS)", the results of the test material were distributed on the scales: "Goals in life. Life process or interest and emotional richness of life. Life performance or satisfaction with self-realization. Locus of control - I (I am the master of life). Locus of control - life or controllability of life" [10]. The questionnaire "Questionnaire of Life-Meaningful Orientations of Student Youth" consisted of questions with ready-made answers, it was necessary to identify the option that would correspond to the opinion of the future teacher. It was necessary to decide on a more significant type of activity, attitude to professional development, factors influencing the path of life, values of life and pleasant experiences that can be acquired, attitude to the educational process as a fact of professional development, spiritual growth, attitude to terminal and instrumental values.

Within the framework of the developed criterion and indicators, as well as a selection of diagnostic tools, the levels of formation of the life-meaning strategies of future teachers were characterized:

- high, characterized by a persistent interest, both in life in general, and in the educational process and professionalization, clear goal-setting, the need for social selfrealization, emotional richness and productivity of life, self-determination and selfdevelopment;

- the middle level is characterized by an unstable interest in matters of professional selfactualization, insufficient cognitive orientation, certainty in significant types of activity, social passivity, emotional enslavement;

- low, characterized by the inability to determine the terminal and instrumental values, lack of interest in professional activity, social passivity and unwillingness to search for life meanings.

In the course of the diagnostics, it was found that $28 \%$ of students have a high level of formation of life-meaning strategies, an average level - $45 \%$ of students, a low level $-27 \%$ of respondents.

The data obtained in the course of the statement testified to the average level of formation of the life-meaning strategies of future teachers, which made it necessary to use at the stage of formation the friend's or accompanying the teacher in the course of organizing the educational and leisure activities of students.

The formative stage of the experiment was an approbation of the technology for the formation of meaningful strategies of a future teacher, a method of friending, which included the support of professional activity, through important lines of influence on the personality, such as: family, science, art, communication, humor, creative work, sports, nature, personal experience of subjects of the educational process.

The expected results were: 
Motivational-knowledge stage: to form a desire to acquire knowledge about the meaning of life, values, goals, ideas about the field of training and education, cognitive needs.

Reflexive-effective stage: to form a desire for self-knowledge, to form an assessment of their actions, deeds, active social contacts, the values of self-actualization, self-acceptance, to form the preservation of their individuality.

At the first stage, the goal was to dispose students to be accompanied and open with the teacher; the tasks of such interaction were to form a positive reaction to the management of meaningful life orientations. The forms of work were open lectures, discussions, conversations, consultations and role-playing games. The forms were presented in a distance format, optional classes were organized in agreement with the students and at a convenient time for them, the duration of meetings was no more than one pair. Themes of lectures and consultations were: "The Phenomenon of the Meaning of Life", "Characteristics of the Meaning of Life", "Biological Factors of Age Development", "Literary Living Room - Discussion of the Meaning of Life in the Works of Russian and Foreign Authors", "Essays - I Live For ...".

In the process of communication, discussions and online lectures, the students were ready to acquaint the experimenter and peers with their hobbies and favorite activity, thus interaction with students was active, proactive, not one-sidedly organized. Joint excursions to nature, hiking along tourist routes, participation in sports competitions as fans took place.

At the second stage of the formation and organization of work with students, forms of interaction were of an integrative nature, meetings became friendly and resembled gatherings at a round table, the students enjoyed participating in interactive games, discussions-reflections, performed training exercises, wrote essays, discussed the viewed films.

Topics of the meetings were: "The optimal meaning of life", "Cases from life - or my vivid memories", "Helpline", "Communication as a condition for self-knowledge", "Life routes", "Professional self-reflection", "Personality and society", "Self-actualization and human behavior". In the process of close interaction, partnerships arose, and students carried away their interests with each other, many quickly switched from one position to another, some included possible new ways of development in their preferences or ideas. With the help of students, groups were opened in social networks, the purpose of which was to interact with the goal of learning, students began to discuss the films they watched, share books that were useful and interesting to read. The students allowed it to be possible to seek advice or hints from the teacher, consultations ceased to be academic in nature, this form of communication can be called partner, friendly. One-sided communication was overcome, it was possible to identify the need and motivational attitudes of a future teacher, touch on the semantic sphere of the personality and determine its impact on professional activity.

In the process of the formative stage of the experiment, it was important to organize feedback with students. Almost after each lesson or organized meeting, there was a product of the activity, so the students wrote mini essays on various topics, this form allowed them to turn to themselves, accept themselves, a letter to the future, was drawn up in the form of a "Map of the Future", the task of such an exercise was see life goals and their agreement with each other. Also, students have created an "interactive navigator" in their professional activities. "The route of life" was presented in the form of an algorithm or a map of the path of personal development, and the time period for each student was different, the goals and motto were varied, the implementation tools were also varied.

During the experiment, the respondents were ready for mutual help, as a result of cooperation and interaction, a group chat was created in VK, where it was possible to send "wishes to each other", this allowed them to see themselves from the outside, and form positive attitudes in themselves in the process of communicating with peers. 
At the control stage of the experiment, a diagnostic section was carried out, the diagnostic tasks were the same as at the primary stage, the questionnaire of V.E. Chudnovsky "On the meaning of life" (Figure 1) [9].

\section{$\equiv$ high $\equiv$ middle $\equiv$ low}

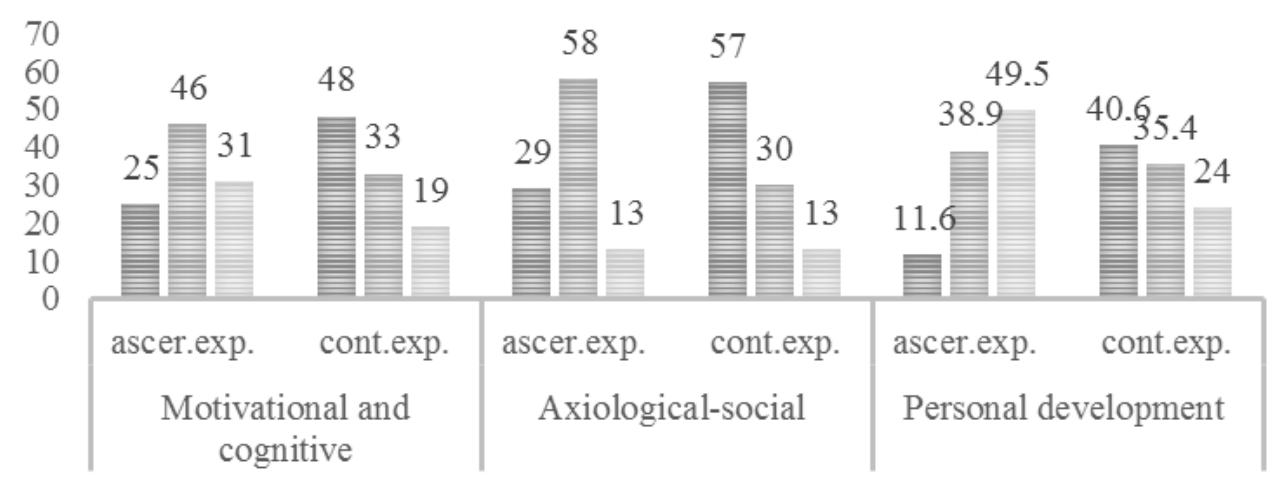

Fig. 1. Comparative data of the control and ascertaining stages of the experiment.

Summing up the above, we can conclude that the work carried out with the participants in the experiment yielded positive results: future teachers are motivated to establish favorable relations in various spheres of social interaction, expand their interpersonal ties, and fulfill their social role; students are ready for friendly interaction with a teacher, future teachers comprehend the importance of realizing their capabilities and abilities, understand the importance of developing their own personality, are ready to make a conscious choice of goals and means of professional activity.

\section{Conclusions}

The formation of life-meaning strategies allows future teachers to build their professional activities, realize their professional interests, build life in accordance with their goals and ideas about its meaning. The conducted research testifies to the interest of future teachers in self-reflection, developed intuition, desire for self-actualization. In terms of friending, the life orientations of student youth are formed on the basis of the semantic translation of personal values, professional and life experience of teachers. This allows achieving organic unity in the development of the professional potential of future teachers, their abilities and communication skills.

Based on the results obtained, we can talk about the advisability of using the proposed program for the formation of life-meaning strategies of a future teacher in the process of friending.

\section{References}

1. G.V. Solovyova, Formation of life-meaning strategies of personality, 1 (2007)

2. A.G. Asmolov, Psychology of personality: Textbook, 367 (1990)

3. P.N. Ermakov, I.V. Abakumova, E.M. Azarko, Features of the personal-semantic sphere of gifted adolescents, Scientific Thought of the Caucasus, 1, 204-212 (2003)

4. A.A. Levshina, Life-meaning strategies of active social behavior of various groups of youth, 223 (2011) 
5. O.V. Telnova, Life-meaning strategies of gifted adolescents, 20 (2007)

6. I.V. Ulyanova, The upbringing system of the formation of life-meaning orientations of secondary school students, 401 (2012)

7. S.V. Shkilev, Life-meaning orientations as a factor of socio-psychological adaptation of students in the process of studying at a university, 19 (2006)

8. D.A. Leontiev, Psychology of meaning: nature, structure and dynamics of meaningful reality, 487 (2003)

9. V.E. Chudnovsky, Formation of personality and the problem of the meaning of life: Selected works, 768 (2006)

10. D.A. Leontiev, Life-meaning orientations test (LSS method), Psychology of happy life access mode: https://psycabi.net/testy/256-test-smyslozhiznennye-orientatsiimetodika-szho-d-a-leontev 